\title{
Artificial language philosophy of science
}

\section{Sebastian Lutz}

Received: 17 October 2010 / Accepted: 3 November 2011 / Published online: 21 December 2011 (C) The Author(s) 2011. This article is published with open access at Springerlink.com

\begin{abstract}
Artificial language philosophy (also called 'ideal language philosophy') is the position that philosophical problems are best solved or dissolved through a reform of language. Its underlying methodology-the development of languages for specific purposes-leads to a conventionalist view of language in general and of concepts in particular. I argue that many philosophical practices can be reinterpreted as applications of artificial language philosophy. In addition, many factually occurring interrelations between the sciences and philosophy of science are justified and clarified by the assumption of an artificial language methodology.
\end{abstract}

Keywords Methodology • Artificial language philosophy • Ideal language philosophy $\cdot$ Ordinary language philosophy $\cdot$ Methodological naturalism • Scientific philosophy $\cdot$ Empirically informed philosophy $\cdot$ Concept formation • Conventionalism $\cdot$ Language choice $\cdot$ Intuition

\section{Introduction}

As there are different methodologies in philosophy, so are there different methodologies in the philosophy of science. This article aims to articulate and defend artificial language philosophy, which has been alternately criticized and ignored in recent times. According to this methodology, philosophical problems are best solved or dissolved by the development of new languages

S. Lutz $(\bowtie)$

Theoretical Philosophy Unit, Utrecht University,

Postbus 80126, 3508 TC Utrecht,

The Netherlands

e-mail: sebastian.lutz@gmx.net 
and concepts, and by the regimentation of existing concepts (Rorty 1967a, Section 2), which has also been called their "improvement" (Carnap 1963, Section 19), "reform" (Maxwell and Feigl 1961), or "explication" (Carnap 1950b, Sections 2-5). ${ }^{1}$

Neither ignored nor as widely criticized as artificial language philosophy is the methodology known as ordinary language philosophy, which is based on the idea that philosophical problems are best solved or dissolved by investigating ordinary language (Rorty 1967a, Section 2; Kauppinen 2007). Even more widely accepted as a philosophical methodology but not as easily circumscribed is naturalized philosophy, roughly the position that philosophical problems are best solved or dissolved through empirical research (Giere 1985; Feldman 2008, Section 2). Probably even more widely accepted, and even less easy to circumscribe, is what I will call, for lack of a better term, 'traditional philosophy'. In the paradigmatic case, traditional philosophy shares with empirical research the aim of arriving at truths about the world, but without direct recourse to empirical methods (cf. Cohnitz and Häggqvist 2009, 9).

These four philosophical methodologies, though probably neither exhaustive nor mutually exclusive, diverge in important ways. The problem of the relation between causation and explanation, for example, could be addressed in artificial language philosophy by suggesting concepts of causation and explanation, while the approach in ordinary language philosophy would be to analyze how the two terms are used in ordinary language. A naturalized approach to the problem might involve an empirical investigation into the neurological, psychological, or sociological phenomena connected to the use of the concepts, whereas in traditional philosophy, one might use intuition as a guide for better understanding the nature of causation and explanation. It would be surprising if all of these methodologies led to the same result (i.e., a solution or dissolution of the problem in a way that is satisfactory within the respective methodology).

It would also be surprising if all of these methodologies led to a philosophy of science whose results are fruitfully connected to the sciences. While it is open for debate whether ordinary language and traditional philosophy fulfill this desideratum for a philosophy of science, naturalized approaches clearly do. But it is further a desideratum for any philosophical methodology that it address philosophical problems, and naturalized approaches to philosophy have often been charged with simply changing the topic. In this article, I will argue that artificial language philosophy of science does fulfill both desiderata.

\footnotetext{
${ }^{1}$ Rorty (1967a) popularized the term 'ideal language philosophy', but as Matteo Collodel, Eric Schliesser, and an anonymous referee have pointed out, the name suggests the existence of a unique ideal language. The term's originator, Bergmann (1949, 439), similarly assumed that there can be one ideal language for all contexts. Since expositors (e. g. Rorty 1967a; Lutz 2009) have applied the term to the works of Carnap and philosophers of a similar inclination, while Carnap $(1963,938)$ himself spoke of the construction of "artificial languages", the term 'artificial language philosophy' seems more apt.
} 
This conclusion also provides a more indirect defense of artificial language philosophy, as I now want to sketch briefly. There are many discussions about philosophical methodology (e.g., Williamson 2007; Papineau 2009), some of which even take into account artificial language philosophy (Rorty 1967b; Lutz 2009). But, arguably, no conclusive defense or criticism has been established about any of the four divergent methodologies. In such a case, a cumulative strategy is often pursued: The individual advantages and disadvantages of each methodology are compared and weighed. For instance, a methodology that yields more results than another in a specific domain has a clear advantage. In the domain of philosophy, naturalized philosophy has been charged with a complete lack of results (cf. Kim 1988), putting it at an immediate disadvantage in any such comparison. Rorty (1967a, 3) discusses the argument that both ordinary and artificial language philosophy have yielded more philosophical results than traditional philosophy, and Carnap (1963, 939f) and Maxwell and Feigl $(1961,491 f)$ argue that artificial language philosophy has yielded more philosophical results than ordinary language philosophy. The following discussion of the status of philosophical results and the relation of science and philosophy of science according to artificial language philosophy suggest another advantage of artificial language philosophy: The methodology leads to results in the domain of meta-philosophy (rather than philosophy) that are not obvious for the other methods. The role of this article's main conclusions in such a cumulative defense of artificial language philosophy is secondary to the conclusions themselves, however. First and foremost, I will argue that the results of artificial language philosophy of science connect fruitfully to the sciences and address philosophical problems.

The rest of this article is structured as follows: After a short overview of the relations between traditional, ordinary language, and naturalized philosophy (Section 2), I provide an outline of artificial language philosophy and its relation to the sciences (Section 3). I then argue that artificial language philosophy can capture much of philosophical practice that ostensibly follows traditional, ordinary language, or naturalized philosophy (Section 4), which suggests that artificial language philosophy addresses philosophical problems. Finally, I show how many relations that have been observed between science and philosophy of science can be justified and clarified within artificial language philosophy (Section 5).

\section{Relations between philosophical methodologies}

\subsection{Traditional philosophy}

Traditional philosophy can be considered an investigation of facts about the world. However, a straightforward empirical investigation of, say, hydrochloric acid differs from the philosophical investigation of causation in that hydrochloric acid has a specific density, decomposes at a specific temperature, and 
generally has properties that can be determined with a certain degree of confidence through measurements and, ultimately, through observations of the outcomes of these measurements. Accordingly, there are experimental ways to determine whether an unknown substance is hydrochloric acid. On the other hand, there is no measurement to determine how causation connects to explanation, and there is no experimental way of determining whether a specific situation or process is an instance of explanation or causation. ${ }^{2}$

In traditional philosophy, intuition is often the analogue of experiments and observations (cf. Sosa 2007, 105). Papineau $(2009,14)$, for example, states that

Gettier appealed to the intuition that a belief whose truth is accidental relative to its method of justification is not knowledge; Kripke appealed to the intuition that something that is not the causal origin of a name is not its bearer; and so on. On my account, all these intuitions are synthetic claims about the relevant kind of scenario.

In other words, these intuitions are about the world. Feigl $(1958,6)$ distinguishes between two kinds of intuitions: "hunches", which can be tested by observations, and "trans-empirical" intuitions, which cannot. If traditional philosophy were to rely on hunches, it would be amenable to empirical test. However, according to Papineau $(2009,18)$ it relies on trans-empirical intuitions:

If my judgemental procedures decide who is a knower by assuming, inter alia, that accidentally true believers are not knowers, then clearly there isn't any question of my meeting up with a case where I judge such an accidentally true believer to be a knower after all. Again, if my judgemental procedures decide what thing bears some name by noting the causal origin of the use of the name, then I'm not going to come across cases where I judge that some name is borne by something other than its causal origin. But this impossibility of direct falsification does not mean that the relevant general assumptions are analytic. They may yet have a substantial synthetic content [...].

For both Papineau (2009, Section IV) and Williamson (2007, Section 6), thought experiments are a core method in traditional philosophy. But while Papineau considers thought experiments to elicit intuitive judgments, Williamson does not distinguish this type of judgment and judgments simpliciter. Williamson $(2007,3)$ holds that "so-called intuitions are simply judgments (or dispositions to judgment)", but thereby brushes over the important distinction between judgments that can be supported by explicit argument or observation and those that cannot be, or at least not completely. Judgments

\footnotetext{
${ }^{2}$ Of course, once the philosophical investigation of, say, causation has resulted in a clear definition (e.g., in the form of a causal search algorithm or via the concept of mark transmission), the definition can be applied to determine whether a situation or process is an instance of causation. I thank Jan Sprenger for asking about the status of causal search algorithms.
} 
that do not have sufficient support are intuitive, and are used analogously to observations. This is actually demonstrated in a brief overview given by Williamson (2007, Section 7.2) of other philosophers' positions on intuition, in which intuitions are always used as premises (rather than conclusions).

It is clear that intuitions in individual thought experiments about, say, the presence or absence of causation or explanation cannot entail a general rule about the relation of causation and explanation. Such a rule has to be either postulated like a scientific hypothesis, or gathered from more general intuitions about the relation itself. The general rule can then be tested against the intuitions in the individual thought experiments, and in the case of inconsistency, the intuitions about either the general rule or the thought experiments have to be modified. This method of testing and revision may be repeated and may eventually lead to a reflective equilibrium, where the intuitions about the general rule and the thought experiments agree (Daniels 2008, Section 1). Testing these intuitions for consistency is a matter of rigorous derivation, ${ }^{3}$ which is used in every philosophical methodology here discussed. How an inconsistency is resolved, however, will rely crucially on the intuitions themselves.

Feigl $(1958,7 f)$ also distinguishes between an intuition and its target, where the intuition is a psychological phenomenon and its target is some fact about the world. Strictly speaking, it is then not the intuition that features in a philosophical argument, but a description of its target or, following the terminology by Fedyk (2009, Section 2), the propositional content of the intuition. When intuitions are considered as psychological phenomena, it is of interest how their occurrence can be established (Feigl 1958, 8-11). If the intuitions under examination belong to a specific class of people (e.g., some group of philosophers, ordinary people, or scientists), then the best method of determining the content of those intuitions seems to be a statistical one. The relevant intuitions may also be those that a specific class of people would have, if presented with some class of facts, considerations, or examples. ${ }^{4}$ Then the best and probably only method of determining the intuitions' content is empirical psychology, which could establish that people in fact usually develop these intuitions. Some parts of traditional philosophy therefore may have to be naturalized.

\subsection{Ordinary language philosophy}

In traditional philosophy, intuitions are taken to provide information about the world; in the terminology of Fedyk (2009, Section 4), they are interpreted as

\footnotetext{
${ }^{3}$ Like in mathematics, a rigorous derivation need not be completely formalized. Of central importance is that it does not rely on unarticulated assumptions.

${ }^{4}$ This may be what Williamson $(2007,191,216)$ has in mind when he speaks of philosophical judgments that require "philosophical training" leading to specific "skills".
} 
world-directed. In ordinary language philosophy, on the other hand, the same intuitions are interpreted as providing information about the language in which the world is described; they are interpreted as meaning-directed. According to Williamson (2007, Section 1), this linguistic turn towards language has been largely superseded by a conceptual turn towards the concepts of thought. While I will discuss only ordinary language philosophy, this discussion is also applicable to methodologies that are based on analyses of the concepts of thought. In what follows, I will rather use 'concept' to refer to the intension of a term, so that a definition or some weaker set of meaning postulates for a term (e.g., 'cause') determines the concept itself (e.g., cause).

If ordinary language philosophy relies on the actual language use of some group, or the actual linguistic intuitions of some group, then one difference between traditional and ordinary language philosophy is straightforward: The claims of traditional philosophy are about unobservable states of the world, while the claims of ordinary language philosophy are about observable states (in the case of actual language use) or states that can be empirically determined with some certainty (in the case of linguistic intuitions). Ordinary language philosophers who rely on their own intuitions to determine the language use or linguistic intuitions of others therefore rely on hunches in Feigl's sense. Of course, whether these hunches are accurate is itself an empirical question, and eventually, the truth of their propositional content has to be established empirically (Feigl 1958, 6f; Mates 1958, 165; Nadelhoffer and Nahmias 2007, 129; Sytsma 2010, Section 1). This also holds for intuitions about the language use or linguistic intuitions that people would have if presented with some class of facts, considerations, or examples. ${ }^{5}$ Some parts of ordinary language philosophy therefore have to be naturalized (Mates 1958). ${ }^{6}$

Like the reliance on intuitions in thought experiments in traditional philosophy, the exclusive reliance on actual language use, that is, individual speech acts, cannot establish general rules about language use. Such general rules may be either stipulated like any other empirical theory or gathered from intuitions about the general rules themselves. Once spelled out explicitly, the general rules may be incompatible with individual speech acts. As in the case of traditional philosophy, such inconsistencies can be established through rigorous derivation. If the method of reflective equilibrium is used to resolve inconsistencies by excluding certain instances of language use or certain general rules, then ordinary language philosophy has a normative component (Carnap 1939, Section 4). In this case, any intuitions about how language should be used are trans-empirical, and the discussion in Section 2.1 applies.

\footnotetext{
${ }^{5}$ This may be what Kauppinen (2007, Section 5) has in mind when he claims that "(philosophical) dialogue and reflection" lead to a convergence of linguistic intuitions.

${ }^{6}$ Arguably, this naturalization leads to experimental philosophy (Lutz 2009, Section 3; Sytsma 2010, Sections 1-3).
} 


\section{An outline of artificial language philosophy}

Like ordinary language philosophy, artificial language philosophy considers philosophical problems to be problems of language. Unlike ordinary language philosophy, however, artificial language philosophy contends that philosophical problems are best solved or dissolved by the conventional prescription of a new language, not by the analysis of actual language use. The new language must be clear enough that an answer to the original question can be rigorously derived (thus leading to a solution), or be such that the problem cannot be formulated (amounting to its dissolution) (Bergmann 1957, 326). An artificial language philosopher may even suggest language reforms for contexts in which there are no problems, either because the resulting language has some pragmatic advantage like greater simplicity or precision, or because this change helps to avoid problems in other contexts (Maxwell and Feigl 1961, 491).

In principle, there is no restriction on the choice of language. As Carnap (1934a, Section 17) states in his "Principle of Tolerance", even the logic of a language is conventional. For what follows, however, it will suffice to outline a very simple case of language choice. I will assume that in addressing the philosophical problems at hand, the logic of the language is taken as fixed, and there is some set $\mathscr{B}$ of basic terms ${ }^{7}$ whose application is taken as unproblematic. It may be taken as unproblematic because the terms apply more or less immediately to observations (cf. Chang 2005), but more generally, the basic terms simply refer to concepts that are not themselves under investigation (Reichenbach 1951, 49; cf. Lewis 1970, 428). The choice of a language then amounts to concept formation, that is, the choice of meaning postulates for the terms not in $\mathscr{B}$. Let me call those terms 'auxiliary terms' and their set ' $\mathscr{A}$ '.

$\mathscr{A}$ can contain terms for pre-theoretically understood concepts whose modification is intended to solve or dissolve the problems at hand. Such a modification is called 'explication', the pre-theoretic concepts are called 'explicanda', and the replacing concepts are called 'explicata' (Carnap 1950b, Sections 2-5). The explicata have to fulfill conditions of adequacy, which identify what problems the newly formed concepts should solve or dissolve, and in what contexts they should be applicable. The contexts are suggested by the pre-theoretic uses of the explicanda (Kuipers 2007, Section 2). ${ }^{8}$ One may, to take a prominent example, consider the use of causation, and search for a new concept that applies only to pairs of events where the description of the first event provides an explanation of the second, and, if the first event is an action, the actor is responsible for the second event. If such a concept was found, it could be used instead of causation, and would relate in a clear way to explanation and responsibility. In this example, 'event', 'explanation', 'action', 'responsibility', etc. are assumed to be in $\mathscr{B}$, but each of these terms can be in

\footnotetext{
${ }^{7}$ In what follows, a term is any non-logical constant of a language.

${ }^{8}$ Therefore, if it is deemed expedient that a previous use of the explicanda is preserved by the explicata, this has to be made explicit in the conditions of adequacy.
} 
$\mathscr{A}$ in other contexts. In general, since the bipartition of terms into $\mathscr{B}$ and $\mathscr{A}$ is context dependent, a term $P$ explicated in one context with the help of a term $Q$ could in another context be used to explicate $Q$.

$\mathscr{A}$ can also contain terms for entirely new concepts, which do not act as explicata. One may, for example, introduce concepts like mark transmission or lawlike generalization simply because they solve some problems in philosophy, not because there are corresponding explicanda. In this case, the conditions of adequacy can be chosen freely and may, for instance, amount to a list of problems that the new concepts should solve.

The choice of the conditions of adequacy is ultimately pragmatic because it depends on the problems that the concepts are meant to solve. The conditions should be precise enough, however, to determine reliably whether they are fulfilled by the concepts. Of two sets of concepts that fulfill all of the conditions, the more fruitful is to be preferred, where Carnap (1950b, 7) judges fruitfulness by the number of results one can establish about the concepts, to which Kemeny $(1963,76)$ adds the number of new research questions that they suggest. This evaluation itself is, of course, deeply pragmatic, since neither every result nor every new problem should count equally.

Carnap (1939, Section 24) provides a general outline of the semantics for a language bipartitioned into basic and auxiliary terms. Przełęcki (1969, Chapters 5f) gives what can be seen as an elaboration of Carnap's account in formal semantics, as do Suppe (1971) and Andreas (2010). ${ }^{9}$ I will briefly summarize Przełęcki's account, since it anticipates the other two, but is more developed and general. Because the basic terms are unproblematic, Przełęcki can assume that their meaning determines a set $\mathbf{B}$ of $\mathscr{B}$-structures. On pain of triviality, B cannot contain all $\mathscr{B}$-structures (Przełęcki 1969, Chapter 4), and thus may lead to a set of meaning postulates $\Pi_{\mathscr{B}}$ for the basic terms, where $\Pi_{\mathscr{B}}$ is the set of $\mathscr{B}$-sentences that are true in every $\mathfrak{B} \in \mathbf{B}$, but not logically true. ${ }^{10}$ A $\mathscr{B}$-sentence $\beta$ thus can have a determined truth value because it follows from or is incompatible with $\Pi_{\mathscr{B}}$. If its truth value differs for different members of $\mathbf{B}$, the truth value of $\beta$ can only be determined by restricting $\mathbf{B}$ through empirical research to a proper subset $\mathbf{E} \subset \mathbf{B} .{ }^{11}$

\footnotetext{
${ }^{9}$ I thank an anonymous referee for the suggestion to discuss the semantic aspects of concept formation.

${ }^{10}$ Carnap (1952) describes how to treat meaning postulates for basic terms on a syntactic level, Przełęcki (1969, Section 10.II) gives a method for introducing meaning postulates for basic terms, and Kyburg (1990) discusses a method for choosing between different sets of meaning postulates for basic terms in probabilistic theories. Note that, if the closure of $\mathbf{B}$ under isomorphism is the class of all $\mathscr{B}$-structures, $\Pi_{\mathscr{B}}=\varnothing$ even though $\mathbf{B}$ itself may not contain all $\mathscr{B}$-structures.

${ }^{11} \mathbf{E}$ is called $\mathbf{M}_{O}^{*}$ by Przełęcki $(1969,42)$, and $\mathbf{B}$ comes closest to what Przełęcki $(1969,43)$ calls 'the characterization of $\mathbf{M}_{O}^{*}$ '. I thank Antje Rumberg and Tom Sterkenburg for helpful discussions on this point. Note that even in the case of exhaustive empirical information, $\mathbf{E}$ may not be a singleton set, since the basic terms may be vague (Przełęcki 1969, Section 5).
} 
Since the auxiliary terms are taken to be problematic, their interpretation is determined solely by $\mathbf{B}$ and the set $\Pi$ of their meaning postulates, which have been chosen to be true in the process of concept formation. For it to be possible to choose $\Pi$ to be true, ${ }^{12}$ it must be possible to expand every structure of $\mathbf{B}$ to a model of $\Pi$, and thus $\Pi$ must be semantically $\mathscr{B}$-conservative (also called ' $\mathscr{B}$-noncreative') with respect to $\Pi_{\mathscr{B}}$ : For every model $\mathfrak{B} \vDash \Pi_{\mathscr{B}}$ of $\Pi_{\mathscr{B}}$, there must be a model $\mathfrak{M} \vDash \Pi$ of $\Pi$ whose $\mathscr{B}$-reduct is $\mathfrak{B},\left.\mathfrak{M}\right|_{\mathscr{B}}=\mathfrak{B}$ (Przelęcki 1969, 98). Otherwise, empirical research could show that there is no model of $\Pi$ that respects the meaning of the $\mathscr{B}$-terms; that is, $\Pi$ could be empirically false.

Since $\Pi_{\mathscr{B}} \cup \Pi$ cannot be shown to be false by empirical research, while the restriction of $\mathbf{B}$ to $\mathbf{E}$ rests solely on empirical research, the latter is clearly synthetic and the former is analytic. This identification of analyticity with conventionality finds its strongest expression in Carnap's Principle of Tolerance, in which logic, the paradigmatic example of analyticity, is taken to be conventional.

In general, a set of postulates for auxiliary terms may be $\mathscr{B}$-creative with respect to $\Pi_{\mathscr{B}}$ and thus not completely analytic. The demarcation criteria for science are a good example of this in philosophy. Such postulates for the term 'science', $S$, are sometimes given by a set $\Theta$ of one sufficient and one necessary condition, $\Theta \models\{\forall x[\varphi(x) \rightarrow S x], \forall x[S x \rightarrow \psi(x)]\}$, which entails the $\mathscr{B}$-sentence $\forall x[\varphi(x) \rightarrow \psi(x)]$ (cf. Lutz 2011). An example from physics is Ohm's law, which contains an analytic component-the meaning postulates for the auxiliary terms 'voltage' and 'internal resistance'-and an empirical component that establishes a relation between the basic terms 'resistance' and 'current intensity' (Simon 1970, Sections 2f). For general finite sets of postulates $\Sigma$ and $\Pi_{\mathscr{B}}=\varnothing$, Carnap (1958, Section 4) proposes identifying their empirical component with their Ramsey sentence $\mathrm{R}_{\mathscr{B}}(\Sigma),{ }^{13}$ which results from $\Sigma$ by existentially generalizing on all $\mathscr{A}$-terms in $\Lambda \Sigma$ and which entails the same $\mathscr{B}$-sentences as $\Sigma$. He suggests identifying the analytic component of $\Sigma$ with what is now called the Carnap sentence $\mathrm{C}_{\mathscr{B}} \mapsto \mathrm{R}_{\mathscr{B}}(\Sigma) \rightarrow \wedge \Sigma$. In the example of the demarcation criteria, $\mathrm{R}_{\mathscr{B}}(\Theta)=\exists X\{\forall x[\varphi(x) \rightarrow X x] \wedge \forall x[X x \rightarrow$ $\psi(x)]\} \models \forall x[\varphi(x) \rightarrow \psi(x)]$. Przełęcki and Wójcicki (1969) and Williams (1973) argue that the Carnap sentence is just the weakest of a number of possible meaning postulates corresponding to a set of postulates. For the example of $\Theta$, $\Pi=\{\forall x[\varphi(x) \wedge \psi(x) \rightarrow S x], \forall x[S x \rightarrow \psi(x)]\}$ is another possibility (Przełęcki and Wójcicki 1969, 391; cf. Przełęcki 1969, Section 7.III).

The set $\mathbf{M}$ of the structures that interpret all terms $(\mathscr{B} \cup \mathscr{A})$ contains all and only those models of the meaning postulates $\Pi$ that expand the structures in $\mathbf{E}$ to $\mathscr{B} \cup \mathscr{A}$; that is, $\mathbf{M}=\left\{\mathfrak{M}|\mathfrak{M}|_{\mathscr{B}} \in \mathbf{E}\right.$ and $\left.\mathfrak{M} \vDash \Pi\right\}$. If $\Pi$ is a singleton set containing the Carnap sentence of some set $\Sigma$ of postulates, the meaning postulates restrict the interpretation of the $\mathscr{A}$-terms only if the postulates' Ramsey

\footnotetext{
${ }^{12} \mathrm{~A}$ set of sentences is true/false if and only if all its elements are true/false.

${ }^{13}$ That is, $\mathbf{E}=\left\{\mathfrak{M} \mid \mathfrak{M} \in \mathbf{B}\right.$ and $\left.\mathfrak{M} \vDash \mathrm{R}_{\mathscr{B}}(\Sigma)\right\}$.
} 
sentence $\mathrm{R}_{\mathscr{B}}(\Sigma)$ is true. The Carnap sentence thus formalizes the assumption that the meaning postulates are motivated by the empirical implications of the postulates in $\Sigma$ and have no relevance for the interpretation of $\mathscr{A}$-terms if the postulates turn out to be empirically false. In other words, while empirical results can show the postulates but not the meaning postulates to be false, they can show the meaning postulates to be useless. Przelęcki and Wójcicki (1969) and Williams (1973) accordingly formalize the weaker assumption that the meaning postulates are motivated by the empirical implications of the postulates but may be applicable even if the postulates turn out to be false. Which assumption is correct will depend on the postulates and the context, as Przełęcki and Wójcicki $(1969,386)$ note (cf. Przełęcki 1969, 76).

There are now three methods of determining the truth or falsity of a sentence $\varphi$ involving auxiliary terms. All of them rely on rigorous derivation, thereby sharing a core aspect with traditional and ordinary language philosophy. In the first method, the analytic truth (or falsity) of $\varphi$ is derived from the meaning postulates $\Pi_{\mathscr{B}} \cup \Pi$. If this is impossible, it may still be possible to derive the result that $\varphi$ is true (or false) in all structures $\mathbf{M}$. Such a derivation would rely on the empirical research that determines E. Finally, if neither method is applicable, new meaning postulates for the terms in $\varphi$ must be developed so that one of the first two methods becomes applicable. This third method thus involves concept formation, making the truth or falsity of $\varphi$ a matter of convention. Since the derivations rely on the meaning postulates and the logic, which have to be chosen by convention, $\varphi$ can be true (or false) for only two reasons: language convention (which determines $\mathbf{B}$ and $\Pi$ ) or empirical research (which determines $\mathbf{E}$ ). If philosophy does not engage in empirical research, this means that all philosophical results are analytic, consisting of language conventions or rigorous derivations that rely on them. Note that rigorous derivations can be important for language choice, since they can reveal otherwise hidden features of a language.

The difference between the first two methods and the last method of determining the status of $\varphi$ illustrates the distinction between "internal" and "external" questions introduced by Carnap (1950a, Section 2). The internal questions are those that rely on a chosen language (in Carnap's terms, a "linguistic framework"), that is, a chosen logic and a chosen set of meaning postulates. Within this language, the investigation of the status of $\varphi$ is objective. For, whether $\varphi$ is true or false depends solely on $\mathbf{E}$ (and thus on the state of the world) and the language, which is fixed. ${ }^{14}$ The third method, that of concept formation, provides a means of answering external questions. Here, the truth or falsity of $\varphi$ is not determined objectively, but rather by convention, and a claim about the status of $\varphi$ cannot be right or wrong, but only more or less practical. There is, in this sense, no fact of the matter.

\footnotetext{
${ }^{14}$ Within a given language, the main tenets of realism would therefore seem true (I thank an anonymous referee for this point).
} 
The preceding considerations are also intended to apply to languages of the sciences (Carnap 1966, 187f): Within a science, it is only possible to test empirically whether some auxiliary term applies in some situation if its application is determined by $\mathbf{E}$ and $\Pi$. In all other cases, science has to engage in concept formation in the same way as philosophy.

Since a scientific theory is developed to accommodate empirical results, its language will have already been chosen for the sake of describing and investigating these results. In fact, the notion of explication is explicitly modeled after concept formation in the sciences (Carnap 1950a, Section 3; Hempel 1952, Section 3). Accordingly, science is teeming with explicata, such as 'temperature' explicating 'warm' (Carnap 1950a, Section 4; Hempel 1952, Section 10), and completely new terms like 'phlogiston', 'oxygen', 'gene', and 'hydrochloric acid', which were introduced to account for phenomena described in basic terms. Therefore it is of interest to establish the scientific language more precisely. Here the methodology of ordinary language philosophy can be very helpful, except that it has to be applied to scientific rather than ordinary language. To avoid exclusive reliance on linguistic hunches, the scientists' actual usage of scientific concepts can be determined empirically (cf. Stotz et al. 2004). In this way, the application of the methodology of ordinary language philosophy would help to fulfill what Reichenbach $(1938,3)$ calls the "descriptive task of epistemology", the search for the rules of scientific language that capture the language intuitions of the scientists. As Waters (2004, Section 3) argues, however, even this descriptive task goes beyond pure observation, for actual usage is often too vague or inconsistent to establish proper rules.

Reichenbach (1938, Section 1) identifies two additional tasks of epistemology. One is the "critical task", the identification and evaluation of inferences. In the terminology of artificial language philosophy, this amounts to rigorous derivation. Next is the "advisory task", the proposal of concepts for use in the sciences. As Waters (2004, Sections 5f) lays out, Reichenbach sees scientists as the final arbiters of language choice, but such a restriction is not inherent in artificial language philosophy in general. For not all philosophers have the same goals as the scientists on whose research they rely.

\section{Philosophical practice in artificial language philosophy}

By design, artificial language philosophy is closely connected to scientific methodology. But it is exceedingly simple to develop a methodology with this feature. Naturalized epistemology (Quine 1969) and experimental descriptivism (Nadelhoffer and Nahmias 2007, Section 2) use neuropsychology to empirically investigate the development and application of concepts, understood as neuropsychological phenomena. Naturalized philosophy of science (Giere 1985) applies sociology to theory choice, understood as a social phenomenon. 
While such methodologies are obviously closely connected to the sciences, it may be that they simply change the subject-that they do not, in fact, address philosophical problems at all (cf. Kim 1988). That naturalized methodologies cannot by themselves solve philosophical problems is also suggested by the possibility to use them as a proper part of traditional and ordinary language philosophy.

A straightforward defense of artificial language philosophy against this charge would require a precise definition of 'philosophical problem' and 'solution to a philosophical problem'. Since neither term has, so far, been defined to general satisfaction, I only aim to show that artificial language philosophy succeeds in capturing many philosophers' posited solutions to philosophical problems, that is, it captures much of philosophical practice. In particular, I will argue that artificial language philosophy can capture many of the applications of the four philosophical methodologies described.

Artificial language philosophy trivially captures its own applications. And in major discussions of the relation between artificial language and ordinary language philosophy (e. g., Carnap 1955, Section 1; Hare 1960, 158; Carnap 1963, Section 19; Kemeny 1963,71,74), there is a general consensus that the results of ordinary language philosophy can be a starting point for the choice of a language (cf. Lutz 2009, 127f). However, exclusive reliance on actual language use would make for an inordinately weak philosophical methodology, for the problem of vague or inconsistent uses of ordinary (and scientific) language cannot be resolved by recourse to the very problematic uses in question. When increasing the precision of a language or resolving its inconsistencies, Maxwell and Feigl $(1961,494)$ argue, an ordinary language philosopher "is actually indulging in tacit reformation and issuing a stipulation as to what the terms in question are to mean". Because of this normative part (which cannot obviously be naturalized), ordinary language philosophy therefore threatens to collapse into artificial language philosophy.

The practices of traditional philosophy can be captured in artificial language philosophy by interpreting alleged discoveries of facts as inventions of new concepts or whole new languages. In the terminology of Carnap (1934b, 13$17,19)$, this means switching from the "material" or "connotative mode of expression" to the "formal mode of expression". When intuitions are used as evidence, they are interpreted as meaning-directed rather than world-directed, and their successive development in the method of reflective equilibrium is interpreted as a method of explication (cf. Kuipers 2007, xiv). However, while traditional philosophy faces the challenge of justifying its claims as discoveries, and thus of explaining how philosophers gain cognitive access to those facts that are the subjects of these claims (e.g., the targets of the philosophers' intuitions), artificial language philosophy can simply justify them as pragmatic language choices.

Indeed, the descriptions of the methods of traditional philosophy by its practitioners sometimes already read like descriptions of artificial language philosophy. Reviewing a critique of traditional metaphysics by Ladyman and 
Ross (2007), Dorr (2010) describes a tentative consensus among metaphysicians about methodology:

It is not enough simply to announce that Xs are more fundamental than Ys: if I want to defend this claim, I am supposed, at a minimum, to (1) introduce a language in which I can talk about Xs without even seeming to talk about Ys; and (2) make some kind of adequacy claim about this language, e. g., that it can express all the genuine facts that we can express using Y-talk, or that all the Y-facts supervene on the facts stateable in the language. For example, if I want to maintain that spacetime is less fundamental than the spatiotemporal relations between bodies, I must describe a language for characterizing these relations, and explain how it can adequately capture, e. g., claims about the global topological structure of spacetime.

Furthermore, Dorr states that one "earn[s] the right" to consider a philosophical problem "dissolved [...] by describing a fundamental language within which no corresponding questions can be formulated". If the "genuine facts that we can express using Y-talk" are taken to determine the contexts in which the X-language should be applicable, Dorr essentially describes the conditions of adequacy on an artificial language as discussed in Section 3.

Dorr (2010) also emphasizes the importance of language choice:

The whole approach [by Ladyman and Ross (2007)] reflects an exaggerated sense of the importance of argument in metaphysics, and a corresponding underestimation of the difficulty of merely crafting a view coherent and explicit enough for arguments to get any grip.

From the perspective of artificial language philosophy, this crafting of a "coherent and explicit" view is nothing but the search for a language in which philosophical problems can be solved by rigorous derivation.

The practices of naturalized philosophy are hard to circumscribe because naturalized philosophy itself is hard to circumscribe, but to the extent that it complements traditional and ordinary language philosophy, artificial language philosophy can capture its practices as well. And to the extent that naturalized philosophy relies on empirical results rather than establishes them (in which case it is sometimes called 'empirically informed philosophy') it is engaged in language choice and rigorous derivation. When it thereby addresses philosophical problems, naturalized philosophy amounts to artificial language philosophy. The one aspect of naturalized philosophy that artificial language philosophy cannot accommodate is empirical research into a non-linguistic phenomenon. For instance, a philosopher who determines the angles of a triangle of light rays over great distances does not describe an explicandum or engage in language choice or rigorous derivation. Such research, however, is often charged with not being philosophy at all.

As an illustration of the reinterpretation of philosophical practice in artificial language philosophy, consider Sosa's response (Sosa 2007, 104) to the 
claim by Nichols and Knobe (2007) that the usage of 'responsible' in ordinary language is inconsistent due to a performance error:

[T] here is an alternative explanation that will cast no affectinvolving doubt on the intuitions in play. This other possibility came to mind on reading their paper, and was soon confirmed in the article on moral responsibility in the Stanford Encyclopedia of Philosophy, where we are told that at least two different senses of 'moral responsibility' have emerged: the attributability sense, and the accountability sense.[...]

So, here again, quite possibly the striking divergence reported above is explicable mainly if not entirely through verbal divergence.

For Sosa $(2007,100)$, the "use of intuitions in philosophy should not be tied exclusively to conceptual analysis. [...] Some such questions concern an ethical or epistemic subject matter, and not just our corresponding concepts". This is presumably how he interprets the "emergence" of two kinds of responsibility: They both exist, but are referred to with the same word, leading to "verbal divergence".

Sosa probably refers to the fall 2004 edition of the Stanford Encyclopedia of Philosophy, in which Eshleman (2004, Section 2.2) writes that

at least some disagreements about the most plausible overall theory of responsibility might be based on a failure to distinguish between different aspects of the concept of responsibility, or perhaps several distinguishable but related concepts of responsibility.

Broadly speaking, a distinction has been drawn between responsibility understood as attributability and responsibility as accountability.

Eshleman's formulation differs from Sosa's paraphrase in that Eshleman considers the disagreements to stem from confusion over "distinguishable but related concepts of responsibility". In other words, there are pre-existing concepts (not pre-existing kinds) that get confused, and an analysis of the concepts of ordinary language would resolve the inconsistency. Regarding such a line of reasoning, Maxwell and Feigl $(1961,489)$ note that there is little reason to think that the two concepts allegedly being confused are somehow already present in ordinary thinking. Certainly, the ordinary user of the term 'responsibility' is not aware of them-otherwise there would be no confusion. And if the ordinary user were to agree with the distinction between the two concepts, Maxwell and Feigl argue, this agreement would amount to a change of language.

According to artificial language philosophy, then, the introduction of the distinction between responsibility as attributability and responsibility as accountability into the philosophical discourse is a conventional change of language - it is not the discovery of a fact about the world or the meaning of the term 'responsibility'. 


\section{The relation between science and artificial language philosophy of science}

That traditional or ordinary language philosophy, partially naturalized or not, leads to fruitful interactions of science and philosophy of science is far from certain. It is, for example, not obvious how insights into the use of a term in ordinary language relate to scientific insights. And while the methodology of ordinary language philosophy can be applied to scientific language to reveal inconsistent usage (Philipse 2009, Section 3), it cannot resolve inconsistencies without threatening to collapse into artificial language philosophy. Traditional philosophy has to establish its own access to facts about the world, besides the scientific route. Williamson (2007, Sections 6, 8) and Papineau (2009, Section IV) consider thought experiments and thus ultimately intuitions to provide this access, but they both rely on contentious claims about the workings of the human mind. In the following, I will argue that the relation between science and artificial language philosophy of science is unstrained.

In a helpful overview, Hansson (2008) describes several ways in which philosophy has been found to relate to scientific disciplines. However, his description conveys only sociological observations about the behavior of philosophers and scientists-even if the observations could be explained on psychological grounds, a justification of the observed relations has to rely on some feature of philosophy itself. I will argue that the relations are justified and clarified when the methodology of artificial language philosophy is assumed.

New empirical results provide material for philosophical investigation Hansson $(2008,477)$ describes a host of influences of scientific disciplines on philosophical work, but his examples mix concept formation, rigorous derivation, and empirical results. With respect to the empirical results, Hansson notes the influence of quantum mechanics and evolutionary biology on philosophy, the influence of psychology and neuroscience on the philosophy of mind, and the influence of linguistics on the philosophy of language. These examples show that some philosophical concepts (in the philosophy of mind, philosophy of language, etc.) are chosen to accommodate empirical results, and thus have to change to remain relevant and fruitful in the light of new results. This is a trivial implication of the way in which languages are chosen in philosophy as well as the sciences.

New rigorous derivations provide material for philosophical investigation Hansson $(2008,477)$ states that results in game and decision theory have provided moral philosophy with new problems for ethical analysis. Such results are established by rigorous derivations based on the language. Because they are not empirical, they can also fall within the domain of philosophy, or they can suggest new language choices in philosophy, for example by revealing previously hidden relations between concepts.

New concepts provide material for philosophical investigation Hansson (2008, 477) further notes that game and decision theory have also provided new 
formulations of old problems in moral philosophy. While moral philosophy is outside the scope of this article, it seems clear that, to use Hansson's examples, psychology, neurosciences, linguistics, quantum mechanics, and biology have all engaged in concept formation. Carnap (1966, 187-189) automatically considers such conceptual work philosophical because it does not involve asserting or testing observational claims. But even with a more restrictive view of philosophy, some philosophical concepts rely on scientific ones (by way of conditions of adequacy, for example), and therefore must be updated whenever there are changes in the scientific concepts. Furthermore, completely new scientific concepts provide new ways for philosophical concepts to be fruitful. Since scientific concepts can also be introduced and changed because of new empirical results, the relation between scientific and philosophical language choice provides yet another way for philosophical concepts to change in light of empirical results.

Methods and issues of philosophy are taken up by other sciences According to Hansson $(2008,477)$, some issues and methods of philosophy have been taken up within other disciplines, for example the investigation of structures of concepts and thought processes in computer science. Since concept formation and rigorous derivation occur in both philosophy and the sciences, it is unsurprising that science can join philosophy in these tasks. The particular proximity of computer science to philosophical research may stem from the computer scientists' need for new languages that capture the structure of concepts and thought processes. But close connections have also formed in the case of formal logic and mathematics, and to a great extent also in the empirical sciences.

Philosophy is part of the community of interdependent disciplines Hansson (2008, Section 3) notes the growing number of interdisciplinary endeavors and concludes on historical grounds that philosophy is part of the "community of interdependent disciplines". Successful philosophical investigations into natural or social phenomena, he claims, have always relied on results from other disciplines (such as the reliance of the philosophy of space and time on relativity theory).

Given the discussion so far, the interdisciplinary nature of philosophical research seems clear, following both from the conditions of adequacy and the demand for the fruitfulness of philosophical concepts. The large role of language choice in the sciences is probably most evident in space-time physics, for relativity theory not only predicts new empirical phenomena, but also suggests new language to accommodate old phenomena in a different way. Philosophers of space and time have had to evaluate this suggestion, and indeed have accepted the superiority of the new language many contexts.

Problems answered experimentally or accurately become non-philosophical Hansson $(2008$, 476f) also reviews the claim that many philosophical topics move into a dedicated field of science once clear answers are at hand. He 
gives the example of psychology, which parted from philosophy after the introduction of experiments.

Since accuracy in the rules for the application of a term is one desideratum of an explication, it is unsurprising that fulfillment of this desideratum often marks the end of philosophical work. Furthermore, empirical research involving auxiliary terms is only possible if there are meaning postulates to connect the auxiliary and basic terms. The split between philosophy and psychology can therefore be seen as the result of the development of a precise language to establish such connections. Of course, once experimental research is pursued, the language can still be modified on the basis of the experimental results. Since a precise language allows for rigorous derivations, Hansson's point also applies, for example, to the parting of mathematics and symbolic logic from philosophy.

The autonomy of applied philosophy According to Hansson (2008, Section 8), the philosophy of science is not an application of epistemology in the way that applied mathematics is an application of pure mathematics. Rather, philosophers of science develop their own theories which are related to-but not derivable from-epistemology.

Hansson's point becomes obvious when considering that epistemology is usually more general than philosophy of science, in that it aims at the explication of terms such as 'belief', 'justification', etc. (and, more generally, the formation of concepts) for as many contexts as possible. Philosophy of science, on the other hand, explicates concepts within the context of scientific theories and scientific practice. Given the different domains, it is to be expected that the explicata differ: Not all contexts that are relevant in epistemology are relevant in the philosophy of science, and some contexts that are very important in the philosophy of science only play a minor role in general epistemology.

Contrary to Hansson's suggestion, there is an analogy between the philosophy of science and applied mathematics, namely when new mathematical concepts are developed for a specific application. A famous example is Dirac's " $\delta$-function", which in fact cannot be treated as a function and led to the development of the theory of distributions. The perception of a disanalogy between the philosophy of science and applied mathematics may rest on a failure to distinguish between rigorous derivations and concept formation. If some concepts apply to a great variety of contexts, then any derivations that involve only these concepts will apply to each of these contexts as well. On the other hand, there is no reason to assume that the concept most fruitful for a great variety of contexts is also most fruitful for each specific one.

Philosophical truths are not eternal Hansson (2008, Section 6) suggests that many philosophers see their discipline as independent of empirical, synthetic results, which have no relevance in the philosopher's realm of eternal, analytic truths. But, Hansson contends, Quine (1963) has shown that there is no uncontroversial line between analytic and synthetic statements, and 
philosophers who ignore empirical results (e.g., relativity theory) to arrive at claims that are "analytically true" (e. g., about time) are often just "demonstrably wrong".

It is understandable that Hansson considers the analytic-synthetic distinction to be a problem for the connection between empirical science and philosophy, since analytically true sentences cannot be demonstrably wrong if such a demonstration would be empirical. This is because the very definition of an analytic truth (as discussed here) is that it has no empirical import. Thus the thorough critiques by Mates (1951), Martin (1952), Kemeny (1963), George (2000), and Loomis (2006) of Quine's attack on the analytic-synthetic distinction may seem to pose a problem. However, the relevance of empirical results for philosophical work can be established without questioning the distinction. As my discussion of the analytic component of postulates in general has shown, meaning postulates are often chosen to be true because of empirical assumptions, and in the case of the Carnap sentence, empirical results are the final arbiter about the relevance of the meaning postulates. In other words, analytical truths cannot be demonstrably wrong, but they can be demonstrably irrelevant.

One might reinterpret Hansson's claim to state that a language chosen without reliance on empirical results is very unlikely to accommodate them better than a language that was chosen with these results in mind. This claim is almost trivially true and suggests that those philosophers who, for instance, do not consider relativity theory when explicating 'time' do not intend their explicatum to accommodate all the empirical results that relativity theory is meant to accommodate.

Philosophy of or with a discipline. With respect to philosophical endeavors related to the sciences, Hansson (2008, Section 7) distinguishes between the philosophy of science and philosophy with science. He states that philosophers of economics, for example, use the "tools of philosophy" to investigate how economists reason, so that philosophers relate to economists very much like social scientists to their objects of study. Philosophy with economics, on the other hand, consists of research conducted in collaboration with economists (for example, on the development of new representations of human beliefs, preferences, and norms).

Clearly, philosophers and scientists can work together when developing the same concepts and rigorously deriving results involving them. This is Hansson's idea of "philosophy with the sciences", and it is to be expected in areas where the foundational concepts have not yet been developed fully, for then the construction of new representations is a major element of research, and rigorous derivations and empirical research cannot yet be pursued independently. Of course, it is also possible to suggest improvements of concepts that have already been explicated in the sciences and used with much success. Such improvements are more likely to occur when dealing with problems that are not at the center of scientific research and thus may not have carried much weight in previous explications. 
There is some unclarity in Hansson's description of "philosophy of science", for he does not specify "the tools of philosophy". But, given his comparison of philosophy of science to social science, Hansson probably has the naturalizable, non-normative part of ordinary language philosophy in mind, as its application would lead to descriptions of the rules of language use in the sciences.

A closer look at the "tools" of artificial language philosophy, i. e. rigorous derivations and language choice, clarifies the possibilities for a "philosophy of science" in Hansson's terminology, and also reveals several relations between science and philosophy of science that are missing from Hansson's list. Within artificial language philosophy, Hansson's philosophy of science is probably best captured as the explication of concepts that are not explicated in the sciences themselves but still used in those contexts, including such general scientific concepts as explanation and probability. These concepts may not connect very well to others, and indeed may be confusing in certain contexts. For example, according to the fine-tuning problem in physics, on the commonly used scales, the range of values under which the universal constants of physics allow life to exist are small. Therefore the existence of life is very improbable, and thus life is in need of an explanation (cf. Ratzsch 2009, Section 4.1). However, the actual usage of 'explanation', 'probability', and 'scale' in the sciences probably does not allow for these inferences. Thus the first step towards a solution of this problem is an explication of the three terms, and this explication would fall within the domain of philosophy. ${ }^{15}$ If the explicata still do not allow for these inferences, the explication of the terms is also the last step.

An example of a discipline-specific scientific concept that, once introduced, has been explicated more extensively in philosophy than in the respective science itself is the notion of gene (cf. Waters 1994). In this case, however, Hansson's distinction between philosophy of and with science becomes very blurry indeed. The explication of such a concept is farther removed from Hansson's philosophy with science when the explication's goals are different from those in the respective discipline, leading to different conditions of adequacy and evaluations of fruitfulness. One instance of this is the explication of an initially discipline-specific concept for simultaneous use in other disciplines. Life, for example, is comparably well-explicated within biology, but not for simultaneous use in robotics. A philosophical inquiry into the implications of artificial life may therefore have to develop its own explicatum. Life may also have to be explicated differently when used in ethical theories, and thus some scientific concepts may need to be explicated for simultaneous use in a non-scientific domain. Waters (2004, Section 6) discusses the conditions

\footnotetext{
${ }^{15}$ Note that it may be necessary to explicate the concepts differently for different scientific domains.
} 
of adequacy for such interdisciplinary explications in depth. Interdisciplinary explications are also desirable if the same term is already used for two slightly different concepts in two different fields, which can lead to fruitful interactions in some circumstances, but also abject confusion in others. 'Information' is a paradigmatic example.

Finally, there are concepts that are not used in the sciences at all, but whose explications must take scientific results into account. Personal identity or free will may not occur (centrally) in the scientific literature, but for many contexts, their explications will have to take into account scientific results about, for example, the functioning of the brain and the predictability of individual behavior.

\section{Conclusion}

According to artificial language philosophy, both science and philosophy of science engage in concept formation and, more generally, language choice, sometimes with the same pragmatic goals and accordingly the same conditions of adequacy and evaluations of fruitfulness. Thus science and philosophy of science can interact and benefit from each other in a variety of ways. It is important to see that in artificial language philosophy of science these interactions and benefits are not simply postulated, but can be justified on methodological grounds.

It is also important to note that many philosophical practices can be reinterpreted to allow artificial language philosophy to use many of the philosophical results yielded by ostensibly competing philosophical methodologies. Specifically, investigations of scientific language in ordinary language philosophy (including naturalized and experimental philosophy) can be interpreted as the identification of the rules of the languages that scientists have developed in order to accommodate their experimental results. Investigations of traditional philosophy can be interpreted as a pragmatic search for a language, rather than facts about the world.

It may be that any philosophical methodology has to be applicable to itselfspecifically, one may take the view that if artificial language philosophy is to be used as a methodology for the philosophy of science, then it also has to be usable for a discussion about philosophy of science. In this case, I consider the above to show that artificial language philosophy of science fulfills two important conditions of adequacy: It makes sense of both philosophical practice and the relations between science and philosophy of science. It can therefore be considered a good choice of language.

Acknowledgements An earlier version of this article was presented at the Future of Philosophy of Science conference at Tilburg University, The Netherlands, in 2010. I thank the participants, Thomas Müller, and two anonymous referees for very helpful comments. I thank Alana Yu for excellent suggestions to improve the clarity and style of the article. 
Open Access This article is distributed under the terms of the Creative Commons Attribution Noncommercial License which permits any noncommercial use, distribution, and reproduction in any medium, provided the original author(s) and source are credited.

\section{References}

Andreas, H. (2010). Semantic holism in scientific language. Philosophy of Science, 77(4), 524-543. Bergmann, G. (1949). Two criteria for an ideal language. Philosophy of Science, 16(1), 71-74.

Bergmann, G. (1957). The revolt against logical atomism-I. The Philosophical Quarterly, 7(29), 323-339.

Carnap, R. (1934a). Logische Syntax der Sprache. Schriften zur wissenschaftlichen Weltauffassung (Vol. 8). Springer-Verlag, Wien. References are to the corrected translation. Carnap, R. (1967). The logical syntax of language. Routledge \& Kegan Paul Ltd, London, reprinted with corrections. Translation by A. Smeaton (Countess von Zeppelin).

Carnap, R. (1934b). On the character of philosophic problems. Philosophy of Science, 1(1), 5-19.

Carnap, R. (1939). Foundations of logic and mathematics. Foundations of the unity of science. Toward an international encyclopedia of unified science (Vol. I,3). Chicago and London: University of Chicago Press. References are to the two-volume edition.

Carnap, R. (1950a). Empiricism, semantics, and ontology. Revue Internationale de Philosophie, 4, 20-40. References are to the slightly modified reprint. Carnap, R. (1956). Meaning and necessity, 2nd ed. Chicago: University of Chicago Press, appendix A.

Carnap, R. (1950b). Logical foundations of probability. Chicago: University of Chicago Press. References are to the 2 nd edition. Carnap, R. (1962). Logical foundations of probability, 2nd ed. Chicago: University of Chicago Press.

Carnap, R. (1952). Meaning postulates. Philosophical Studies, 3(5), 65-73.

Carnap, R. (1955). Meaning and synonymy in natural languages. Philosophical Studies, 6(3), 33-47.

Carnap, R. (1958). Beobachtungssprache und theoretische Sprache. Dialectica, 12, 236-248.

Carnap, R. (1963). Replies and systematic expositions. In P. A. Schilpp (Ed.), The philosophy of Rudolf Carnap. The library of living philosophers (Vol. 11). Chicago and LaSalle, IL: Open Court Publishing Company (pp. 859-1016).

Carnap, R. (1966). Philosophical foundations of physics: An introduction to the philosophy of science, edited by M. Gardner. New York and London: Basic Books, Inc.

Chang, H. (2005). A case for old-fashioned observability, and a reconstructed constructive empiricism. Philosophy of Science, 72(5), 876-887.

Cohnitz, D., \& Häggqvist, S. (2009). The role of intuitions in philosophy. Studia Philosophica Estonica, 2.2, 1-14. http://www.spe.ut.ee/ojs-2.2.2/index.php/spe/article/view/84/53. Special issue: The role of intuitions in philosophical methodology, edited by D. Cohnitz and S. Häggqvist.

Daniels, N. (2008). Reflective equilibrium. In E. N. Zalta (Ed.), The Stanford encyclopedia of philosophy (fall 2008 ed.). Stanford University, Stanford: The Metaphysics Research Lab, Center for the Study of Language and Information. http://plato.stanford.edu/archives/ fall2008/entries/reflective-equilibrium/.

Dorr, C. (2010). Review of Ladyman and Ross (2007). In G. Gutting \& A. F. Gutting (Eds.), Notre Dame philosophical reviews. Notre Dame, IN: Philosophy Department, University of Notre Dame. http://ndpr.nd.edu/review.cfm?id=19947.

Eshleman, A. (2004). Moral responsibility. In E. N. Zalta (Ed.), The Stanford Encyclopedia of philosophy (fall 2004 ed.). Stanford: The Metaphysics Research Lab, Center for the Study of Language and Information, Stanford University. http://plato.stanford.edu/archives/ fall2004/entries/moral-responsibility/.

Fedyk, M. (2009). Philosophical intuitions. Studia Philosophica Estonica, 2.2, 54-80. http://www. spe.ut.ee/ojs-2.2.2/index.php/spe/article/view/57. Special issue: The role of intuitions in philosophical methodology, edited by D. Cohnitz and S. Häggqvist.

Feigl, H. (1958). Critique of intuition according to scientific empiricism. Philosophy East and West, $8(1-2), 1-16$. 
Feldman, R. (2008). Naturalized epistemology. In E. N. Zalta (Ed.), The Stanford encyclopedia of philosophy (fall 2008 ed.). Stanford: The Metaphysics Research Lab, Center for the Study of Language and Information, Stanford University.

George, A. (2000). On washing the fur without wetting it: Quine, Carnap, and analyticity. Mind, 109(433), 1-24.

Giere, R. N. (1985). Philosophy of science naturalized. Philosophy of Science, 52(3), 331-356.

Hansson, S. O. (2008). Philosophy and other disciplines. Metaphilosophy, 39, 472-483.

Hare, R. M. (1960). Philosophical discoveries. Mind, 69(274), 145-162.

Hempel, C. G. (1952). Fundamentals of concept formation in empirical sciences. Foundations of the unity of science. Toward an international encyclopedia of unified science (Vol. II,7). Chicago and London: University of Chicago Press. References are to the two-volume edition.

Kauppinen, A. (2007). The rise and fall of experimental philosophy. Philosophical Explorations, 10(2):95-118.

Kemeny, J. G. (1963). Analyticity versus fuzziness. Synthese, 15(1), 57-80.

Kim, J. (1988). What is "naturalized epistemology"? Philosophical Perspectives, 2, 381-405.

Kuipers, T. A. F. (2007). Introduction. Explication in philosophy of science. In T. A. F. Kuipers (Ed.), General philosophy of science-Focal issues. Handbook of the philosophy of science (Vol. 1). Amsterdam: Elsevier (pp. vii-xxiii).

Kyburg, Jr., H. E. (1990). Theories as mere conventions. In C. W. Savage (Ed.), Scientific theories. Minnesota studies in the philosophy of science (Vol. 14). Minneapolis, MN: University of Minnesota Press (pp. 158-174).

Ladyman, J., \& Ross, D. (2007). Every thing must go: Metaphysics naturalized (with David Spurrett and John Collier). Oxford: Oxford University Press.

Lewis, D. (1970). How to define theoretical terms. The Journal of Philosophy, 67(13), 427-446.

Loomis, E. J. (2006). Empirical equivalence in the Quine-Carnap debate. Pacific Philosophical Quarterly, 87, 499-508.

Lutz, S. (2009). Ideal language philosophy and experiments on intuitions. Studia Philosophica Estonica, 2.2,117-139. http://www.spe.ut.ee/ojs-2.2.2/index.php/spe/article/view/65. Special issue: The role of intuitions in philosophical methodology, edited by D. Cohnitz and S. Häggqvist.

Lutz, S. (2011). On an allegedly essential feature of criteria for the demarcation of science. The Reasoner, 5(8), 125-126. http://www.kent.ac.uk/secl/philosophy/jw/TheReasoner/vol5/ TheReasoner-5(8).pdf.

Martin, R. M. (1952). On 'analytic'. Philosophical Studies, 3, $42-47$.

Mates, B. (1951). Analytic sentences. Philosophical Review, 60, 525-534.

Mates, B. (1958). On the verification of statements about ordinary language. Inquiry, 1, 161-171.

Maxwell, G., \& Feigl, H. (1961). Why ordinary language needs reforming. The Journal of Philosophy, 58(18), 488-498.

Nadelhoffer, T., \& Nahmias, E. (2007). The past and future of experimental philosophy. Philosophical Explorations, 10(2), 124-149.

Nichols, S., \& Knobe, J. (2007). Moral responsibility and determinism: The cognitive science of folk intuitions. Noûs, 41, 663-685.

Papineau, D. (2009). The poverty of analysis. Aristotelian Society Supplementary Volume, 83(1), 1-30.

Philipse, H. (2009). Can philosophy be a rigorous science? Royal Institute of Philosophy Supplement, 84, 155-176.

Przełęcki, M. (1969). The logic of empirical theories. Monographs in modern logic series. London/New York: Routledge \& Kegan Paul/Humanities Press.

Przełęcki, M., \& Wójcicki, R. (1969). The problem of analyticity. Synthese, 19(3-4), 374-399.

Quine, W. V. O. (1963). Two dogmas of empiricism. In Quine, W. V. O. From a logical point of view. Logico-philosophical essays, 2nd ed. Harper \& Row, New York (pp. 20-46).

Quine, W. V. O. (1969). Ontological relativity and other essays. The John Dewey essays in philosophy (No. 1). New York and London: Columbia University Press.

Ratzsch, D. (2009). Teleological arguments for God's existence. In E. N. Zalta (Ed.), The Stanford encyclopedia of philosophy (winter 2009 ed.). Stanford: The Metaphysics Research Lab, Center for the Study of Language and Information, Stanford University. http://plato.stanford.edu/ archives/win2009/entries/teleological-arguments/.

Reichenbach, H. (1938). Experience and prediction; an analysis of the foundations and the structure of knowledge. Chicago: University of Chicago Press. 
Reichenbach, H. (1951). The verifiability theory of meaning. Proceedings of the American Academy of Arts and Sciences, 80(1), 46-60.

Rorty, R. (1967a). Introduction: Metaphilosophical difficulties of linguistic philosophy. In Rorty, R. (Ed.), The linguistic turn: Recent essays in philosophical method. Chicago and London: University of Chicago Press (pp. 1-39).

Rorty, R. (Ed.) (1967b). The linguistic turn: Recent essays in philosophical method. Chicago and London: University of Chicago Press.

Simon, H. A. (1970). The axiomatization of physical theories. Philosophy of Science, 37, 16-26.

Sosa, E. (2007). Experimental philosophy and philosophical intuition. Philosophical Studies, 132(1), 99-107.

Stotz, K., Griffiths, P. E., \& Knight, R. (2004). How scientists conceptualize genes: An empirical study. Studies in History and Philosophy of Biological and Biomedical Sciences, 35(4), 647-673.

Suppe, F. (1971). On partial interpretation. The Journal of Philosophy, 68(3), 57-76.

Sytsma, J. (2010). The proper province of philosophy: Conceptual analysis and empirical investigation. Review of Philosophy and Psychology, 1(3), 427-445. Special issue: Psychology and experimental philosophy (part II), edited by E. Machery, T. Lombrozo, \& J. Knobe.

Waters, C. K. (1994). Genes made molecular. Philosophy of Science, 61(2), 163-185.

Waters, C. K. (2004). What concept analysis in philosophy of science should be (and why competing philosophical analyses of gene concepts cannot be tested by polling scientists). History and Philosophy of the Life Sciences, 26(1), 29-58.

Williams, P. M. (1973). On the conservative extensions of semantical systems: A contribution to the problem of analyticity. Synthese, 25(3-4), 398-416.

Williamson, T. (2007). The philosophy of philosophy. The Blackwell/Brown lectures in philosophy (Vol. 2). Malden, MA: Blackwell Publishing. 